\title{
Optimización de la biorremediación en relaves de cianuración adicionando nutrientes y microorganismos
}

\author{
Optimization of cyanidation tailings bioremediation adding nutrients and \\ microorganisms
}

Laboratorio de Biotecnología Ambiental, Facultad de Ciencias y Filosofía, Universidad Peruana casetano Her Eaver doil Jasmin Hurtado: jasminhurtado@yahoo.com $\begin{array}{ll}\text { Presentado: } & 24 / 01 / 2012 \\ \text { Aceptado: } & 07 / 10 / 2012\end{array}$ $\begin{array}{ll}\text { Aceptado: } & \text { 07/10/2012 } \\ \text { Publicado online: } & \text { 10/11/2012 }\end{array}$

\section{Jasmin Hurtado y Arturo Berastain}

\section{Resumen}

El objetivo del presente trabajo fue encontrar los parámetros óptimos para el desarrollo de los proceso de bioremediacion de relaves de cianuración, mediante experimentos factoriales a nivel de columnas con la adición de nutrientes y el empleo de bacterias sulfato reductoras (BSR) para estabilizar iones metálicos mediante la formación de sulfuros y bacterias capaces de biodegradar cianuro (BC). Se aislaron BSR de relave y se usó un inoculo previamente aislado de BC. Se realizó una prueba de adaptación a relave y una prueba en columnas para probar: (1) el efecto del empleo de 1 y $10 \mathrm{mM}$ de lactato para incrementar la actividad de BSR; y (2) adición de 0,1 y $1 \mathrm{mM}$ de acetato de sodio y ácido fosfórico para mejorar la actividad de BC. Con las mejores condiciones encontradas se realizó una prueba a nivel de columnas donde se adicionó un cultivo mixto (BSR-BC) y una mezcla de lactato y acetato en concentraciones de $1 \mathrm{mM}$ y $10 \mathrm{mM}$. Se encontró que los nutrientes incrementaban la reducción de sulfatos un $48 \%$ en promedio y la adición de inoculo un $42 \%$. La bioremediacion de cianuro se mantuvo en $12 \%$ sin efecto en la adición de nutrientes o inoculo. Se probó en dos relaves adicionales y la adición de lactato de sodio $1 \mathrm{mM}$ permitió la inducción de BSR en 8 días en uno de ellos.

Palabras claves: cianuro; relaves; BSR; sulfuros; biorremediación.

\section{Abstract}

The objective of this project was to find optimum parameters for the development of bioremediation process of cyanidation tailings by addition of nutrients and microorganisms. It was tested the use of sulfate-reducing bacteria (SRB) to stabilize metal ions through the formation of sulphides and; bacteria able to biodegrade cyanide (BC). Factorial experiments were conducted at level of columns. SRB from Cyanidation tailings were isolated and $\mathrm{BC}$ proceeded from pregnant solution of cyanidation. BSR and BC were adapted to tailings. A column test was performed to try: 1 . the effect of using 1 and $10 \mathrm{mM}$ lactate to increase the activity of BSR and 2. Addition of 0,1 and $1 \mathrm{mM}$ sodium acetate and phosphoric acid to improve the activity of BC. In order to optimize parameters, it was tested in columns, effect of a mixed culture (SRB-BC) and nutrients ( $1 \mathrm{mM}$ lactate and Acetate $1 \mathrm{mM}$ ). Nutrients were found to increase the reduction of sulfate to $48 \%$ (average) and the addition of inoculums to $42 \%$. Bioremediation of cyanide was $12 \%$. It was not shown effect on the addition of nutrients or inoculums on Cyanide degradation. Two additional tailings were tested and the addition of $1 \mathrm{mM}$ sodium lactate allowed the induction of BSR in 8 days in one of them.

Keywords: Cyanide; tailings; SRB; sulphides; bioremediation.

\section{Introducción}

Los relaves de cianuración provienen del empleo de cianuro en el tratamiento de minerales para la recuperación de metales valiosos y presentan dos problemas químicos por un lado el contenido de sulfatos de metales diversos y por otro el remanente de cianuro que queda después de los procesos de recuperación de metales, ambos vinculados a graves daños a la salud humana y ambiental.

El empleo de microorganismos es una alternativa para descontaminar los relaves de cianuración, muchos de ellos son bacterias sulfato reductoras (BSR) que producen sulfuro de hidrógeno el cual reacciona con los sulfatos en solución produciendo sulfuros de metal los cuales son estables y pueden precipitar (White \& Gadd, 1996), además se conocen otros microorganismos con capacidad de degradar cianuro (BC) (Knowles 1976; LuqueAlmagro 2005; Rivera \& Hurtado 2001).

Las bacterias sulfato reductoras están siendo usadas en empresas relacionadas con metales para el tratamiento de aguas de descarga a nivel industrial (Lawrence \& Marchant 2006; Scheeren et al. 1992) y en ecosistemas de humedales para trata- miento de aguas ácidas (De Bolder 2003). Para la degradación del cianuro se han desarrollado varios procesos, pero a la fecha solo la compañía Homestake Mining ha desarrollado procesos para la biodegradación de cianuro a nivel industrial, el más antiguo de ellos viene operando desde 1989 (Witlock 1990).

No se conocen estudios que combinen el empleo de cultivos mixtos formados por microorganismos que degraden los cianuros complejos liberando los iones en solución, y que a la vez permitan la estabilización de estos mediante la formación de sulfuros de metal empleando bacterias sulfato reductoras en relaves de cianuración.

El empleo de microorganismos en medios definidos en procesos de descontaminación es conocido, sin embargo las interacciones que suceden en ellos necesitan más estudios, por ejemplo el efecto de agregar nutrientes específicos a los ambientes mineros; aunque si existen experiencias agregando nutrientes para tratar compuestos tóxicos en otras actividades productivas (Atlas \& Bartha 2002, Scherr et al. 2011)

El objetivo del presente trabajo fue obtener información relacionada al uso de nutrientes (lactato, acetato y ácido fosfórico) y 
microrganismos (BSR-BC) que pueden ser utilizados en procesos de biorremediación de relaves de cianuración. En una primera fase se usó un diseño factorial para optimizar de manera independiente la reducción de sulfatos y la degradación de cianuro procedente de un relave de cianuración, y en una segunda fase se intentó optimizar ambos procesos en conjunto. Finalmente, se evaluó en otros dos relaves el mejor resultado obtenido, en la inducción de la actividad de bacterias sulfato reductoras.

\section{Material y métodos}

Microorganismos.- Las bacterias reductoras de sulfato (BSR) fueron aisladas de relaves de cianuración proporcionados por la Compañía minera Orcopampa (15²16'S, 72¹9'W). El medio utilizado para el aislamiento fue el medio de Baars Modificado (Starkey 1938), el cual tiene la siguiente composición (en g/L): $\mathrm{KH}_{2} \mathrm{PO}_{4}, 0,5 ; \mathrm{NH}_{4} \mathrm{Cl}, 1,0 ; \mathrm{MgSO}_{4} .7 \mathrm{H}_{2} 0,2,0 ; \mathrm{CaSO}_{4}, 1,0$; $\mathrm{FeSO}_{4} .7 \mathrm{H} 20,0,05$; lactato de sodio $(70 \%), 3,5$; extracto de levadura, 1,0 y citrato de sodio, 5,0. El pH fue ajustado a $7 \mathrm{con}$ $\mathrm{NaOH}(10 \% \mathrm{w} / \mathrm{v})$. Se sembraron muestras de $1 \mathrm{~g}$ de cada relave en $9 \mathrm{~mL}$ de medio de Baars modificado y se colocaron en cámaras de anaerobiosis con sistemas de generación de anaerobiosis AnaeroGen de 2,5 L (Oxoid) a $30^{\circ} \mathrm{C}$.

Las muestras fueron mantenidas durante 2 semanas y repicadas en medios empleando el mismo sistema de anaerobiosis. Se monitoreo el crecimiento mediante microscopía y formación de sulfuro de fierro (ennegrecimiento de medio).

Las cepas utilizadas para biorremediación de cianuro (BC) fueron tres cepas de Pseudomonas sp. las cuales fueron previamente aisladas de una solución cargada de cianuración utilizadas en procesos de biorremediacion de estas soluciones (Freyre 2000), las cuales fueron mantenidas en medio PGY con la siguiente composición (en g/L): peptona, 2,5; glicerol, 1,25; extracto de levadura, 0,25; agar 15,0. El pH fue ajustado a 9,0.

Muestras de relave de cianuración.- Tres muestras de relaves de cianuración fueron proporcionadas por la empresa $\mathrm{BH}$ Consultores entre mayo de 2008 y junio de 2009. La muestra de relave 1, tenía la siguiente composición (en mg/L): Ag 0,23; $\mathrm{Cu}$ 19,3; S 891; Sb 4; cianuro Total 193; cianuro WAD 0; cianuro libre 0 y sulfatos 3070 . Los relaves 2 y 3 tenían 939 y $4279 \mathrm{mg} / \mathrm{L}$ de sulfatos respectivamente.

La muestra 1 fue utilizada para la determinación de los parámetros óptimos. Los relaves 2 y 3 fueron ensayados en los parámetros optimizados.

Análisis Químicos.- Los análisis de sulfatos fueron realizados empleando el método 4500-SO $4^{2}$ - C Sulfate. Gravimetric Method with Ignition of Residue (APHA, AWWA y WEF 1999). El cianuro total fue determinado por la Técnica colorimétrica 4500-CN-N Total Cyanide after destilation (APHA, AWWA y WEF 1999). El análisis se llevó a cabo con espectrofotómetro Hewlett Packard 6453.

Adaptación de bacterias a relave 1 a nivel de frascos.- La adaptación de bacterias sulfato reductoras al relave 1 se realizó sembrando las bacterias aisladas en frascos conteniendo $50 \mathrm{~mL}$ de relave, $50 \mathrm{~mL}$ de medio Baars y $10 \mathrm{~mL}$ de inoculo BSR. Se preparó controles en las mismas condiciones sin inoculo. Los frascos fueron mantenidos en cámaras de anaerobiosis con sistemas de generación de anaerobiosis AnaeroGen a $20{ }^{\circ} \mathrm{C}$ durante 4 semanas. Se realizaron coloraciones y conteo de bac- terias empleando microscopio de contraste de fases. Asimismo, se sembró $0,1 \mathrm{~mL}$ del cultivo en medio líquido de Baars en anaerobiosis para verificar la presencia y actividad de bacterias sulfato reductoras.

Para adaptar las bacterias biodegradadoras de cianuro al relave 1 , se sembraron frascos conteniendo $50 \mathrm{~mL}$ de relave, $50 \mathrm{~mL}$ de medio PGY y $10 \mathrm{~mL}$ de inoculo BC. Se preparó un frasco control sin bacterias. Los frascos fueron sellados con parafilm y mantenidos a $20^{\circ} \mathrm{C}$ durante 4 semanas. Se realizaron verificaciones periódicas del crecimiento mediante coloraciones GRAM y conteos.

Efecto de nutrientes e inoculo en la reducción de sulfatos y biodegradación de cianuro de relave 1 a nivel de columnas.Se determinó mediante un diseño factorial $2^{2}$ el efecto del nivel de adición de nutrientes e inoculo. Se montaron 3 grupos de columnas. En el primer grupo se estudio el efecto de lactato de sodio e inoculo BSR en la reducción de sulfatos. En el segundo y tercer grupo se determinó el impacto de: (1) la adición de acetato de sodio e inoculo BC y (2) la adición de ácido fosfórico e inoculo $\mathrm{BC}$ en la degradación de cianuro.

Para cada grupo, se montaron 8 columnas de vidrio de 235 $\mathrm{mm}$ de altura por $30 \mathrm{~mm}$ de diámetro las cuales fueron llenadas completamente con $120 \mathrm{~mL}$ de relave.

Para comprobar el efecto en la reducción de sulfatos, se agregó de acuerdo al diseño, solución stock de Lactato de sodio hasta dar una concentración final de $1 \mathrm{mM}$ y $10 \mathrm{mM}$ y como inoculo $1 \mathrm{~mL}$ de cultivo de bacterias sulfato reductoras.

La verificación del efecto de acetato de sodio en la biodegradación de cianuro se realizó empleando una solución stock hasta llegar a una concentración final de 0,$1 ; 1 \mathrm{mM}$ y $1 \mathrm{~mL}$ de bacterias degradadoras de cianuro.

El efecto del ácido fosfórico fue estudiado empleando una solución stock hasta una concentración final de 0,$1 ; 1 \mathrm{mM}$ y 1 $\mathrm{mL}$ de bacterias degradadoras de cianuro. Se montaron además dos columnas control solo con relaves.

Las columnas fueron cubiertas con parafilm y permanecieron estáticas y a $20^{\circ} \mathrm{C}$ durante 4 semanas. Terminadas las 4 semanas, las soluciones fueron analizadas para cianuro total y sulfatos.

Determinación de los parámetros óptimos para la biodegradación de cianuro y reducción de sulfatos en relave 1 a nivel de columnas.- Se empleo un diseño factorial $2^{2}$ para determinar el efecto del nivel de adición de acetato de sodio y lactato de sodio e inoculo mixto (BSR-BC). Se montaron 8 columnas de vidrio de $350 \mathrm{~mm}$ de altura por $50 \mathrm{~mm}$ de diámetro las cuales fueron llenadas completamente con $600 \mathrm{~mL}$ de relave.

Para comprobar el efecto en la reducción de sulfatos, se agregó de acuerdo al diseńo, una solución stock de lactato de sodio y acetato de sodio hasta dar un volumen final de $1 \mathrm{mM}$ y $10 \mathrm{mM}$ de lactato de sodio y como inoculo $5 \mathrm{~mL}$ de cultivo mixto de bacterias $(2,5 \mathrm{~mL}$ de bacterias degradadoras de cianuro y 2,5 $\mathrm{mL}$ de bacterias reductoras de sulfato). Se montaron además dos columnas control sin nutrientes ni inoculo.

Las columnas fueron cubiertas con parafilm y permanecieron estáticas y a $20^{\circ} \mathrm{C}$ durante 4 semanas. Terminadas las 4 semanas, las soluciones fueron analizadas para cianuro total y sulfatos. 
Tabla 1.Valores estadísticos descriptivos de los valores dependientes (concentración de sulfato y cianuro) en las 3 pruebas de la primera fase (Efecto) y las 2 pruebas de la segunda fase (Optimización).

\begin{tabular}{|c|c|c|c|c|c|c|}
\hline \multicolumn{2}{|c|}{ Puebas } & \multicolumn{5}{|c|}{ Concentracion de valores dependientes (mg/L) } \\
\hline Valor Dependiente & Factor & $\mathbf{n}$ & Minimo & Maximo & Media & Desv. Tip. \\
\hline \multirow{2}{*}{ Sulfato } & Lactato-BSR & 10 & 1600 & 3067 & 2205 & 528 \\
\hline & Optimizacion & 10 & 1390 & 3067 & 2122 & 571 \\
\hline \multirow{3}{*}{ Cianuro } & Acetato-BC & 10 & 120 & 186 & 150 & 19 \\
\hline & Fosforo-BC & 10 & 126 & 186 & 157 & 23 \\
\hline & Optimizacion & 10 & 144 & 186 & 159 & 12 \\
\hline
\end{tabular}

Efecto de la adición de nutrientes en la inducción de bacterias sulfato reductoras en los relaves 2 y 3.- Se colocaron en tubos de prueba (por triplicado) $2 \mathrm{~g}$ de relave y $10 \mathrm{~mL}$ de solución con 0,$5 ; 1$ y 2 mM de lactato de sodio y otro set con 2 , 1, y 0,5 de acetato de sodio. A los tubos se les coloco papeles embebidos en acetato de plomo (Gerardt et al. 1981). Se colocaron los tubos en una jarra de anaerobiosis a $30^{\circ} \mathrm{C}$ durante 1 mes. La inducción de bacterias sulfato reductoras fue evidenciada por la formación de sulfuro de plomo en las tiras de acetato de plomo.

Análisis Estadístico.- Se realizaron análisis estadísticos usando SPSS versión 14. Inicialmente se calcularon los valores estadísticos descriptivos (valores mínimo, máximo, promedio y desviación) y se verifico la normalidad de la distribución de las mediciones de las concentraciones de cianuro y sulfato con la prueba de Kolgomorov-Smirnov, presentándose una distribución normal. Posteriormente se aplicó la prueba de Levene y la de ANOVA factorial utilizando como variables dependientes las concentraciones de cianuro y sulfato y como factores, el empleo de nutrientes y adición de inoculo. Todas las pruebas se trabajaron con un nivel de significancia de 0,05.

\section{Resultados}

Aislamiento de bacterias sulfato reductoras.- La siembra de relaves en medio liquido de Baars produjo un ligero ennegrecimiento del medio a los 5 días, el cual se intensifico gradualmente hasta encontrarse el medio completamente negro debido a la formación de sulfuro de hierro, por la producción de sulfuro de hidrógeno.

En coloración Gram se encontraron bacilos Gram negativos.

Crecimiento y actividad de bacterias sulfato reductoras en frasco con relave 1.- En la prueba final se observó la presencia de bacilos Gram negativos. Asimismo, el cultivo del medio produjo formación de sulfuros (color negro), que nos está indicando la presencia de bacterias sulfato reductoras creciendo con relave 1.
Crecimiento y actividad de bacterias degradadoras de cianuro en frasco con relave 1.- Se observó en las revisiones periódicas, presencia de $5 \times 10^{8}$ células $/ \mathrm{mL}$ de microorganismos con morfologías semejantes a las cepas inoculadas. En la muestra control se pudo encontrar una población de $10^{5}$ células $/ \mathrm{mL}$. Aparentemente la población natural de la solución de cianuración incrementada por la adición del medio de cultivo.

Efecto del lactato de sodio y del inoculo en la reducción de sulfatos en relave 1 a nivel de columnas.- En la Tabla 1 se pueden observar los valores estadísticos descriptivos de todas las pruebas realizadas a nivel de columnas.

La Tabla 2 muestra los resultados de la aplicación de lactato e inoculo BSR en la reducción de sulfatos. El porcentaje promedio de reducción de sulfato en estas condiciones fue de 34\% (1069 mg/L). El control de columnas de relave sin ninguna adición, produjo una disminución de sulfatos en solución del $1 \%(70 \mathrm{mg} / \mathrm{L})$.

El análisis factorial $2^{2}$ de los resultados presentados en la Tabla 2, muestra que la variación de la adición de Lactato de sodio $1 \mathrm{mM}$ a $10 \mathrm{mM}$ aumenta la concentración de sulfato en solución en $500 \mathrm{mg}$ en promedio y que la adición de inoculo disminuye la concentración de sulfato en solución en $100 \mathrm{mg} / \mathrm{L}$. La reducción de sulfato se ve incrementada de manera estadísticamente significativa cuando se emplea $1 \mathrm{mM}$ de lactato de sodio y cuando se produce una interacción de lactato e inoculo.

Efecto de nutrientes e inoculo en la degradación de cianuro de relave 1 a nivel de columnas.- Del análisis de los resultados obtenidos sobre degradación de cianuro presentados en la Tabla 3, se muestra que en la primera serie de pruebas que emplea acetato de sodio, la degradación aumenta cuando se emplea $1 \mathrm{mM}$ de acetato de sodio, sin embargo no hay una diferencia significativa entre emplear $0,1 \mathrm{mM}$ y $1 \mathrm{mM}$. Si hay una diferencia estadísticamente significativa cuando se emplea inoculo BC y hay interacción entre acetato e inoculo.

Tabla 2. Porcentaje de la reducción de sulfatos en relave 1 a nivel de columnas obtenidos en la primera fase. Los resultados mostrados son el promedio de pruebas por duplicado.

\begin{tabular}{|c|c|c|c|c|c|}
\hline \multicolumn{2}{|c|}{ Matriz de experimentos } & \multicolumn{2}{|c|}{ Plan de Experimentación } & \multirow{2}{*}{ Sulfato $\mathrm{mg} / \mathrm{L}$} & \multirow{2}{*}{ \% Reducción de sulfato } \\
\hline $\mathrm{X} 1$ & $\mathrm{X} 2$ & Lactato de sodio $\mathrm{mM}$ & Inoculo BSR (mL) & & \\
\hline- & - & $1 \mathrm{mM}$ & $\mathrm{NO}$ & 1625 & 48 \\
\hline+ & - & $10 \mathrm{mM}$ & NO & 2400 & 22 \\
\hline- & + & $1 \mathrm{mM}$ & SI & 1876 & 39 \\
\hline+ & + & $10 \mathrm{mM}$ & SI & 2100 & 33 \\
\hline \multicolumn{2}{|c|}{ Control } & NO & NO & 3063 & 1 \\
\hline
\end{tabular}


Tabla 3. Porcentaje de degradación del cianuro en el relave 1 a nivel de columnas obtenidos en la primera fase. Los resultados mostrados son el promedio de pruebas por duplicado.

\begin{tabular}{|c|c|c|c|c|c|c|}
\hline \multirow{2}{*}{\multicolumn{2}{|c|}{$\begin{array}{c}\text { Matriz de } \\
\text { experimentos }\end{array}$}} & \multicolumn{3}{|c|}{ Plan de Experimentación } & \multirow{3}{*}{ CN- Total (mg) } & \multirow{3}{*}{$\begin{array}{l}\text { \% degradación } \\
\text { de cianuro }\end{array}$} \\
\hline & & \multicolumn{2}{|c|}{ Nutrientes (X1) } & \multirow{2}{*}{$\begin{array}{c}\text { Inoculo BC } \\
\text { (X2) (mL) }\end{array}$} & & \\
\hline X1 & $\mathrm{X} 2$ & $\begin{array}{l}\text { Acetato de sodio } \\
\text { (mM) }\end{array}$ & $\begin{array}{l}\text { Acido fosfórico } \\
\text { (mM) }\end{array}$ & & & \\
\hline- & - & 0,1 & 0 & No & 162 & 16 \\
\hline+ & - & 1 & 0 & No & 138 & 28 \\
\hline- & + & 0,1 & 0 & $\mathrm{Si}$ & 129 & 34 \\
\hline+ & + & 1 & 0 & $\mathrm{Si}$ & 144 & 25 \\
\hline- & - & 0 & 0,1 & No & 136 & 27 \\
\hline+ & - & 0 & 1 & No & 128 & 33 \\
\hline- & + & 0 & 0,1 & $\mathrm{Si}$ & 181 & 6 \\
\hline+ & + & 0 & 1 & $\mathrm{Si}$ & 150 & 22 \\
\hline & & No & No & No & 178 & 8 \\
\hline
\end{tabular}

En el segundo conjunto de pruebas (en las cuales se empleo ácido fosfórico) se obtienen mejores resultados significativos de degradación de cianuro, cuando se utiliza $1 \mathrm{mM}$ de ácido fosfórico sin inoculo.

Los controles con relave mostraron una disminución de cianuro total del $8 \%(15 \mathrm{mg} / \mathrm{L})$. Por lo tanto, el porcentaje promedio de reducción de cianuro, eliminado el degradado de manera natural en el control, fue de $20 \%$ (38 mg/L) cuando se emplea acetato, mientras que el porcentaje promedio de reducción de cianuro es $14 \%(27 \mathrm{mg} / \mathrm{L})$ cuando se emplea fósforo. Debido al incremento de reducción producida por la adición de acetato de sodio, se decidió seguir con las pruebas empleando acetato de sodio a concentraciones mayores e inoculo BC.

Determinación de los parámetros óptimos para la biodegradación de cianuro y reducción de sulfatos de relave 1.- El promedio de la reducción de sulfato fue de 34\%(1044 mg/L). Se encontró diferencias significativas entre las condiciones empleadas en las columnas en cuanto a la reducción de sulfato en solución (Tabla 4).

El promedio de disminución de cianuro fue de $12 \%$ (23 $\mathrm{mg} / \mathrm{L})$. El análisis del contenido de cianuro total en solución no mostró diferencias estadísticamente significativas cuando se usó inoculo mixto ni cuando se agregó nutrientes, sin embargo si hubo una diferencia significativa cuando se produjo interacción de nutrientes e inoculo.
Se obtuvo 55\% (1390 mg/L) de reducción de sulfato en solución cuando se agrego $1 \mathrm{mM}$ de nutrientes e inoculo mixto. Cuando se agregó $1 \mathrm{mM}$ de nutrientes al relave 1 , se encontró $15 \%$ menos de sulfato en solución que cuando se agrego $10 \mathrm{mM}$ de los nutrientes. Cuando se agregó inoculo mixto a los relaves se encuentra un $8 \%$ más de sulfato en solución que cuando no se agrega inoculo al relave 1 .

El factor más importante fue el agregar nutrientes (lactato y acetato) y el efecto más resaltante fue la reducción de sulfatos, por lo cual se decidió probar la adición de lactato de sodio y acetato de sodio en la inducción de bacterias sulfato reductoras a diferentes concentraciones en los 2 relaves adicionales.

Efecto de la adición de nutrientes en la inducción de bacterias sulfato reductoras en los relaves 2 y 3.- Se trabajó con 2 relaves de cianuración de diferentes procedencias. En el relave 2 no se pudo evidenciar la presencia la actividad de bacterias sulfato reductoras en los 30 días que duró la prueba. En el relave 3, que contaba con un contenido de sulfatos de 4279 $\mathrm{mg} / \mathrm{L}$ se demostró la presencia de bacterias sulfato reductoras, al agregarse lactato de sodio (Tabla 5).

\section{Discusión}

Las bacterias sulfato reductoras son un grupo muy diverso de procariotas que usan la reducción desasimilatoria de sulfato para la generación de energía, por lo que nuestro estudio se dirigió a investigar su actividad.

Tabla 4. Sumario del ANOVA de resultados de la optimización de factores (lactato, acetato e inoculo mixto) en la concentración de sulfato (mg/L).

\begin{tabular}{lcccc}
\hline Fuente & Suma de cuadrados tipo III & gl & F & Significacion \\
\hline Modelo corregido & 724375 & 3 & 2143 & 0.000 \\
Interseccion & 28505025 & 1 & 253096 & 524 \\
Inoculo & 61075 & 1 & 1 & 4010 \\
Nutrientes & 451725 & 1 & 1878 \\
Nutrientes*Inoculo & 211575 & 4 & 0.000 \\
Error & 450 & 8 & 7 & \\
Total & 29229851 & 724825 & & \\
Total corregida & & & \\
\hline
\end{tabular}


Tabla 5. Efecto de la adición de Lactato o acetato en la inducción de bacterias sulfato reductoras en el relave 3 . La tabla muestra el resultado de pruebas por triplicado.

\begin{tabular}{lcc}
\hline \multirow{2}{*}{ Prueba } & $\begin{array}{c}\text { Inicio de Producción de } \mathbf{H}_{2} \mathbf{S} \\
\text { en el relave 3 (Días) }\end{array}$ \\
\hline \multicolumn{2}{c}{ Control } & Negativo \\
\hline Lactato de & $0,5 \mathrm{mM}$ & 16 \\
Sodio & $1 \mathrm{mM}$ & 8 \\
& $2 \mathrm{mM}$ & 8 \\
Acetato de & $0,5 \mathrm{mM}$ & Negativo \\
Sodio & $1 \mathrm{mM}$ & Negativo \\
& $2 \mathrm{mM}$ & Negativo \\
\hline
\end{tabular}

Las concentraciones empleadas de lactato de sodio y el uso de acetato de sodio con el objeto de incrementar la reducción de sulfatos, están basadas en los estándares empleados en los medios de cultivo para favorecer el crecimiento de microrganismos (Freyre 2000, Starkey 1938), mientras que la concentración de fosfato fue la misma utilizada en el trabajo de Withlock (1990). En este trabajo, se ha confirmado, que existe efecto de estimulación de la actividad de microrganismos en relaves de cianuración, que es producido por la adición de lactato principalmente, incluso en concentraciones menores de las publicadas.

Se conocía que la adición de $10 \mathrm{mM}$ de acetato y $10 \mathrm{mM}$ de lactato bioestimulan la población de BSR, produciendo mayores velocidades de reducción de sulfuros en suelos contaminados con uranio y metales pesados (Sitte et al. 2010), también que, en aguas ácidas artificiales, el incremento de celulosa produce un incremento en la actividad de las bacterias sulfato reductoras (Bechard et al. 1993). En nuestro trabajo la concentración de 1 $\mathrm{mM}$ de acetato, lactato o fosfato produjeron la disminución de sulfatos o cianuro, y en la degradación de cianuro tuvo el mayor efecto el acetato que el fosfato.

El lactato es un compuesto comúnmente usado en el aislamiento de BSR. La utilización del acetato divide a las bacterias sulfato reductoras en dos grandes grupos, aquellas que degradan compuestos orgánicos hasta acetato y las que degradan compuestos orgánicos, incluyendo al acetato, hasta $\mathrm{CO}_{2}$ (Strattan 2010). En las bacterias sulfato reductoras, el lactato sirve como aceptor de electrones para la recuperación de metales, el lactato o acetato como fuente de carbono y el sulfato como aceptor de electrones (White \& Gadd 1996). Como hemos demostrado el lactato ańadido a los relaves incremento la producción de sulfuro de hidrógeno, porque las bacterias sulfato reductoras oxidan el lactato y usan el hidrógeno producido para la reducción de sulfuros (Muyzer \& Stams 2008). El uso de lactato $1 \mathrm{mM}$ produjo el mayor efecto llegándose a un $47 \%$ de reducción de sulfatos.

En las pruebas a nivel de columnas se favorece la producción de anaerobiosis en zonas o nichos anóxicos que permiten la degradación de sulfatos. Algunas especies de bacterias sulfato reductoras pueden resistir bajas concentraciones de oxígeno, aunque la reducción de sulfatos es anaeróbica (Muyzer \& Stams 2008), además reducción de sulfatos puede ocurrir en hábitats oxigenados en los cuales se forman nichos anóxicos (Sitte 2010)

El efecto de la adición de inóculos depende de los microorganismos presentes en ellos y de los ambientes involucrados.
La adición de bacterias sulfato reductoras fue el segundo efecto significativo más importante incrementando la reducción de sulfatos a un $42 \%$. La adición de un inóculo de bacterias degradadoras de cianuro no tuvo un efecto significativo en la disminución de la concentración de cianuro en la solución podría deberse a diferentes motivos. Primero, el inóculo BC empleado para la degradación de cianuro en esta prueba, fue aislado de una solución cargada de cianuración y la aplicación de este inoculo BC permitió la disminución del 88\% (584 $\mathrm{mg} / \mathrm{L}$ ) de cianuro total (Freyre 2000); pero estos microrganismos podrían no funcionar de manera eficiente con relaves o soluciones de otras minas, ya que la composición química y mineralógica de cada relave y solución cargada esta basada en la composición del mineral y, sus características físicas (granulometría, porcentaje de sólidos, etc.) dependen de los procesos de concentración del mineral (Velarde 1992). Segundo, cuando se trabajo solo con un inoculo BC se obtuvo en promedio $23,5 \%$ de disminución de cianuro, a diferencia de cuando se empleo un inoculo mixto en el cual se obtuvo $11 \%$ de disminución, lo cual podría haber sido causado por efecto de competencia entre poblaciones nativas presentes en las columnas o de interacción de los inóculos BC y BSR, hay reportes de fallas en los procesos de bioaugmentación debido a competencia entre poblaciones (Thompson et al. 2005, Van Veen et al. 1997). Por otro lado, la degradación de cianuro observada en la muestra control podría deberse a la actividad de poblaciones observadas presentes naturalmente en el relave de cianuración y que podrían haberse incrementado por la adición del acetato de sodio o el ácido fosfórico. Finalmente, se pudieron haber generado factores físico químicos adversos para el inoculo $\mathrm{BC}$ por las condiciones de trabajo en columnas.

En las pruebas realizadas con los relaves 2 y 3 , se comprobó inducción de las BSR en el relave 3, por la adición de lactato de sodio $1 \mathrm{mM}$ en un tiempo más corto que cuando se emplearon concentraciones menores, la cual sería la dosis adecuada para ese relave; lo que demostraría que dependiendo del relave, la adición de nutrientes para incrementar la actividad microbiana y la biorremediación de relaves de cianuración es una opción fácil de aplicar, económica y de establecimiento sencillo.

Cada relave de cianuración tiene características físico-químicas específicas, lo cual condicionaría la presencia de diferentes poblaciones naturales microbianas en cada relave que habría que tener en consideración para la aplicación de inóculos. Asimismo, habría que considerar la realización de un estudio a largo plazo ya que ha sido demostrado por Zagurya et al. (2004) que los relaves de cianuración son ambientes cambiantes debido a cambios naturales de $\mathrm{pH}$ y población, por lo que habría que comprobar el efecto de las adiciones de nutrientes y/o inóculos en las diferentes condiciones producidas.

Aunque tenemos un mejor entendimiento sobre el papel de la disponibilidad de nutrientes para acelerar los procesos microbianos, aún debemos de caracterizar las poblaciones microbianas envueltas en el proceso de biorremediación de estos relaves y determinar el papel de otros nutrientes en el control del proceso de biorremediación estudiado.

\section{Agradecimientos}

El presente trabajo fue realizado gracias al apoyo del Concytec (Proyecto PROCYT 236-2008). 


\section{Literatura citada}

American Public Health Association (APHA), American Water Works Association (AWWA) y Water Environment Federation (WEF). 1999. Standard Methods for the Examination of Water and Wastewater $20^{\text {th }}$ Edition. pp 4-176, 4-50.

Atlas R. \& R. Bartha. 2002. Ecologia Microbiana y Microbiologia Ambiental. 2da.edn. Prentice Hall Hispanoamericana. Pp. 562-597.

Bechard G., S. Rajan \& W.D.Gould. 1993. Characterization of a Microbiological Process. In: BioHydrometallurgical technologies.. A.E. Torma, M.L. Apel \& C.L. Brierley, eds. The Minerals, Metals \& Material Society.

De Bolder P. 2003. Metal Bioavailability and speciation in a wetland tailings Repository Amended with Biosolids Compost, Wood Ash and sulfate. J. Environ. Qual. 32: 851-864

Freyre Antuane. 2000. Biodegradación de desechos de cianuración producidos en la industria minera. Tesis para optar el título de Licenciado en Ciencias con mención en Química. Universidad Peruana Cayetano Heredia.

Gerhardt P., R.G.E. Murray, R,N, Costilow et al.1981. Manual of Methods for General Bacteriology. American Society for Microbiology. Pp 456-458.

Knowles 1976. Microorganisms and cyanide. Bacteriol. Rev.40:652680.

Lawrence R \& B. Marchant. 2006. Developments and new applications for biogenic sulphide reagent in hydrometallurgy and Mineral processing. Hidroprocess, Santiago. Chile.

Luque-Almagro V. 2005. Bacterial degradation of cyanide and its metal Complexes under alkaline conditions. Appl. Environ. Microbiol. 71:940-947.

Muyzer, G. \& A.J.M. Stams. 2008. The ecology and biotechnology f sulphate-reducing bacteria. Nature Rev. Microbiol. 6:441-454

Rivera J. \& J. Hurtado. 2001. Solid media for isolation of ferrocyanide degrading microorganisms. Proceedings of International Biohydrometallurgical Symposium IBS-2001, Brasil.

Scheeren P.J.H, R.O. Koch, N. Buisman et al. 1992. New Biological Tretament for heavy metal contaminated ground water. Trans. Instn. Min. Metall. ( Sect. C. Mineral Process. Extr. Metall.) 101:C190-C199
Scherr K.E, M. M. Nahold, W. Landschbauer \& A.P.Loibner. 2011. Sequential application of electron donors and humic acids for the anaerobic bioremediation of chlorinated aliphatic hydrocarbons, New Biotech. 29: 116-125

Sitte J., D.M. Akob,C. Kaufman et al. 2010. Microbial Links between Sulfate Reduction and Metal Retention in Uranium and Heavy Metal-Contamined Soil. Appl. Eviron. Microbial. 76:3143-3152

Starkey RL. 1938. A study of spore formation and other morphological characteristics of Vibrio desulfuricans. Arch. Mikrobiol. 9: 268-304,

Strattan D.J. 2010 .Quantifying the expression of dissimilatory sulfite reductase as a metric for sulfate reduction rates. Thesis Submitted in partial fulfillment of the requirements for the degree of Master of Science in Geology in the Graduate College of the University of Illinois at UrbanaChampaign. $<$ http://www.ideals.illinois.edu/bitstream/ handle $/ 2142 / 16814 / 3$ Strattan_Derik.pdf?sequence $=5>$ Acceso 23/12/2011.

Thompson I.P., C.J.Van der Gast, L.N. Ciric \& A.C. Singer 2005. Bioaugmentation for bioremediation: the challenge of strain selection. Env. Microbiol.7:909-915.

Van Veen J.A., L.S. van Overbeek \& J.D. van Elsas. 1997. Fate and activity of microorganisms introduced into soil. Microbial Molecul. Biol. Rev. 61:121-135

Velarde C. 1992. La minería en el Peru. Editores Tecnicos Asociados. Peru

White C. \& G.M. Gadd. 1996. Mixed sulphate-reducig bacterial cultures for bioprecipitation of toxic metals: factorial and response-surface analysis of the effects of dilution rate, sulphate and substrate concentration. Microbiology. 142: 2197-2205.

Witlock James. 1990. Biological process in mining: Present and future. Western regional Conference. Lead S.D. Sept.

Zagureya G.J., K. Oudjehanib \& L. Deschenesb. 2004. Characterization and availability of cyanide in solid mine tailings from gold extraction plants. Sci. Total Environ. 320:211-224 